This document is the preprint version of the published article in Qualitative Health Research. Final publication is available from SAGE Publishing:

https://doi.org/10.1177/1049732316679372

Wagner, V., Bertrand, K., Flores-Aranda, J., Acier, D., Brunelle, N., Landry, M., et Brochu, S. (2017). Initiation of addiction treatment and access to services: Young adults' accounts of their help-seeking experiences. Qualitative Health Research, 27(11), 1614-1627 https://doi.org/10.1177/1049732316679372 


\section{Initiation of Addiction Treatment and Access to Services: Young Adults' Accounts of their Help-Seeking Experiences}

Short title: Young Adults' Initiation of Addiction Treatment

Vincent Wagner ${ }^{1,2}$, Karine Bertrand ${ }^{2}$, Jorge Flores-Aranda ${ }^{2}$, Didier Acier ${ }^{1}$, Natacha Brunelle $^{3}$, Michel Landry ${ }^{4}$, and Serge Brochu ${ }^{5}$

${ }^{1}$ Laboratoire de Psychologie des Pays de la Loire, Department of Clinical Psychology, Université de Nantes, Nantes, France

${ }^{2}$ Addiction Studies and Research Program, Faculty of Medicine and Health Sciences, Université de Sherbrooke, Longueuil, Québec, Canada

${ }^{3}$ Department of Psychoeducation, Université du Québec à Trois-Rivières (UQTR), Trois-Rivières, Québec, Canada

${ }^{4}$ Montreal Addiction Rehabilitation Centre - University Institute, Montréal, Québec, Canada

${ }^{5}$ School of Criminology, Université de Montréal, Montréal, Québec, Canada 
* Corresponding author:

Vincent Wagner

Laboratoire de Psychologie des Pays de la Loire, Faculté de Psychologie, Université de Nantes, Chemin de la Censive-du-Tertre, BP 81227, 44312 Nantes Cedex 3, France

E-mail: vincent.wagner@univ-nantes.fr 


\title{
Initiation of Addiction Treatment and Access to Services: Young Adults' Accounts of their Help-Seeking Experiences
}

Short title: Young Adults' Initiation of Addiction Treatment

\begin{abstract}
Substance addiction in young adults is particularly problematic. Yet, much remain at stake in understanding the specifics of this population's access to services. The objective of this study is to explore young adults' initiation of substance abuse treatment. Our study sample was composed of 35 individuals aged 18 to 30 with problematic psychoactive substance use who have been identified in criminal courts, hospital emergency departments and Health and Social Services Centers in Quebec (Canada). A thematic analysis was performed on the 62 semi-structured interviews conducted with participants. Three components emerged. First, personal elementsexpectations, individual motivations, perceptions of use and capacity to control itinfluence initiation of substance abuse treatment. Second, family and peers have noticeable influences. Finally, system characteristics and prior care experiences also shape the process. Consideration should be given to tailor interventions that can reach young adults and encourage them to initiate appropriate care.
\end{abstract}




\section{Keywords}

Substance misuse; young adults; access to treatment; service use trajectory; qualitative research 


\section{Introduction}

There are multiple negative consequences associated with excessive use of psychoactive substances such as cannabis and alcohol: cognitive impairment and/or psychosocial development disorders, impacts on physical health, risk of other addictions, and even road accidents (United Nations, 2014; Authors, 2014). However, it should be noted that despite the development of care provision and regardless of the country in question, few substance-dependent adults effectively seek treatment to overcome their substance use problems (Perron et al., 2009; Rotondi \& Rush, 2012; Saunders, Zygowicz, \& D’Angelo, 2006; Xu, Rapp, Wang, \& Carlson, 2008). Over the past few decades, many researchers have looked at low utilization of health services. Several theoretical models have been developed to define the concept of access to care, especially in the medical, mental health and addiction fields (Andersen, 1995; Pescosolido, Gardner, \& Lubell, 1998; Prochaska, DiClemente, \& Norcross, 1992; Saunders et al., 2006). More recently, Levesque, Harris, and Russell (2013) suggested a multidimensional conceptualization to better grasp the process of access to health care that takes into account interactions with multiple dimensions. They define access to health care as the intersection of structural aspects of the health system, service provision and features of individuals. By extension, this concept supports greater understanding of variations in access to care, which can help determine influences of potential factors on treatment initiation and engagement. 
Some studies have focused on access to treatment of young substance usersadolescents, emerging adults or young adults (Gogel, Cavaleri, Gardin, \& Wisdom, 2010; Hawkins, 2009; Leslie, 2008; Wisdom, Cavaleri, Gogel, \& Nacht, 2011; Wu, Blazer, Li, \& Woody, 2011). Those studies call attention to the real public health issues that substance abuse within this population constitutes. Moreover, in Canada, prevalence of psychoactive substance misuse seems to be particularly important in young men from 15 to 24 years old (Pearson, Janz, \& Ali, 2013), the emerging adults (Arnett, 2000). Emerging adulthood is a significant period of human development, during which solicitation of substance consumption - between peers for instance - may be numerous. In addition, vulnerability to the consequences of substance abuse increases during transition to adulthood, a pivotal and stressful period in a person's social and neurobiological development (Arnett, 2000; Beaujot \& Kerr, 2007; Leslie et al., 2015).

More precisely, some research have looked at trajectories of substance use and service utilization by comparing individual substance users' characteristics, including age (Evans, Li, Grella, Brecht, \& Hser, 2013; Parthasarathy \& Weisner, 2005). For instance, Parthasarathy and Weisner (2005) show that in their sample — users aged 17 to 29-differ from older users: less utilization of primary care and less compliance to proposed substance abuse treatment. A recent study highlights quite similar results (Schuman-Olivier, Weiss, Hoeppner, Borodovsky, and Albanese, 2014). Young adults 
seem to face greater challenges initiating and staying engaged in care, compared to older adults or even, adolescents. Mechanisms different from those present in older adults may influence younger users' substance abuse treatment trajectory (Hoeppner, Hoeppner, and Kelly, 2014).

Given these differences, young adults users can express particular needs and encounter specific difficulties that caregivers do not necessarily take into account (Hoeppner, Hoeppner, \& Kelly, 2014; Smith, Godley, Godley, \& Dennis, 2011) and which may explain why it seems particularly challenging for these users to come and stay in treatment (Schuman-Olivier et al., 2014). Moreover, some personal, sociofamilial (i.e. personal and familial beliefs on substance use and/or substance misuse treatment, fear of stigma, of non-confidentiality of care, etc.) and institutional factors (i.e. lack of prevention structure, of early interventions tailored to young adults, direct and indirect costs of care, delays, training and attitude of professionals, etc.) may act as barriers and hinder young adults' initial access to treatment (Adler, Pritchett, Kauth, \& Mott, 2015; Choi, DiNitto, \& Marti, 2014; Hawkins, 2009; Priester et al., 2016; Sterling, Weisner, Hinman, \& Parthasarathy, 2010). On this subject, some researchers suggest that it is important to investigate these specificities in order to offer even more tailored interventions to young adults' needs (Hawkins, 2009; Smith et al., 2011). In addition, Orford (2008) regrets that substance users' own perspectives on their uses and 
on their help-seeking behaviors weren't sufficiently the focus of studies designed to better understand psychoactive substance misuse treatment services trajectories.

Therefore, the objective of this study is to explore-considering the very own users' perspective - the process of substance abuse treatment initiation. Precisely, we'll focus here on the first step of a treatment process, among perhaps multiple past service utilizations - of young adults with problematic alcohol or drug use.

\section{Methods}

\section{Study Framework}

This qualitative study is part of a broader research program supported by the Community-University Research Alliance Program of the Social Sciences and Humanities Research Council of Canada (Authors, 2014; Authors, 2015). The purpose of the program is to study links between addiction trajectories and service utilization trajectories, from the points of view of users.

The current study uses a descriptive phenomenological perspective (Bloor \& Wood, 2006; Giorgi, 2005). It is a qualitative exploration of the subjective treatment access experiences of psychoactive substance users aged 18 to 30 . The objective is to clarify the meaning of a particular phenomenon - in this case, access to treatment - to ultimately design tailored interventions. 


\section{Sample}

The sample recruited for the larger project included 127 participants, whose problematic substance use was detected at one of the points of entry in Montréal (a highly urbanized area) and Mauricie-Centre-du-Québec (a mixed rural, semi-urban and urban area): criminal courts, hospital emergency departments and Health and Social Services Centers. Those three places are known to be frequent contact points with problematic substance users. There, individuals are detected and referred to specialized structures. Among the entire sample, $41 \%$ reported one or less consultation among specialized addiction services during the last 5 years, mostly following the recent detection episode, despite long lasting alcohol and drug problems (Authors, 2014, p.90). On the other hand, nearly $60 \%$ were twice or more in addiction services during the same period (Authors, 2014, p.91). For purposes of the present study-focusing on young adults—only participants aged 18 to 30 were retained $(n=35 / 127)$.

Table 1 presents our sample's assorted demographic characteristics. The mean age of the sample is 24.68 years $(S D=3.44) .74 .3 \%$ of the participants are male $(n=$ 26), $65.7 \%$ are single $(n=23)$, and $71.4 \%$ have no children $(n=25)$. The sample seems fairly distributed considering the area of recruitment: $48.6 \%$ of participants come from the area of Montréal and 51.4\% come from the area of Mauricie-Centre-du-Québec. Most of the sample was detected in the criminal justice system (i.e. 65.7\%). 
(Insert Table 1)

\section{Material}

A semi-structured-recorded-research interview lasting about 1 1/2 hours explored different themes related to addiction trajectories and participants' service utilization. Young adults were asked about changes in their consumption, the impact of services on those changes as well as their experiences with the identification process, referral and treatment at their initial involvement with services and during the previous five years. Most young adults in the sample $(77.1 \% ; n=27)$ were met a second time a year later, for a total of 62 interviews. The second interview used the same interview grid, which provided supplemental data and enabled us to add information about addiction and service utilization trajectories since the first interview of each participant. Each participant signed an information and consent form before starting the interview. At the end, they were given CAN\$25 as financial compensation, as approved by the Human Health Research Ethics Committee of the X (n09-188-R1) and the Addiction Research Ethics Committee (\#MP-CÉRT-CDC-IUD-009-001).

In order to gain an extensive description of the sample, alcohol and drug use had been assessed with standardized instrument, the DEBA-Alcool/Drogues questionnaire (Tremblay, Rouillard, \& Sirois, 2004). The scope of this questionnaire is the detection and assessment of the need for drug-related and alcohol-related support. The DEBA- 
Alcool/Drogues consists in two separate scales, one for alcohol and one for drugs, and takes around ten minutes to complete. Its design included two validated scales- the French version of the Severity of Alcohol Dependence Data Questionnaire (Raistrick, Dunbar, \& Davidson, 1983) and the French version of the Severity of Dependence Scale (Gossop et al., 1995) — and several questions especially created by the original authors (Tremblay et al., 2004).

Finally, a descriptive questionnaire measured substance treatment services use (Authors, 2009).

\section{Analysis Strategies}

Means and frequency distributions were used to describe the sociodemographic characteristics of the sample (i.e. age, sex, recruitment area, points of entry, marital status, highest level of education completed, annual personal income and children). Using data from the DEBA-Alcool/Drogues and the descriptive questionnaire measuring substance treatment services use, description — via percentages - of the sample levels of substance use and treatment services use was undertaken.

A thematic content analysis of all interview transcriptions was performed using NVivo 9.0. The objective of this type of analysis was to pinpoint recurring pertinent elements, group them into categories, and identify points of convergence and divergence in the discourses. As a result, a mixed coding grid (predefined based on the 
interview grid and integrating interview contents) was set up (Miles \& Huberman, 2003; Paillé \& Mucchielli, 2003) and included a coding guide designed for the various analysts. An intercoder agreement was used on $9 \%$ of the total material collected (i.e. 18 interviews) to verify and adjust the coding grid and guide. Final percentages of intercoder agreement were high, varying between $90.1 \%$ and $98.7 \%$. In-depth analyses were also performed to highlight points of convergence and divergence in the various transcriptions while specifically considering the themes that had been coded (Authors, 2014): reasons for variations in consumption; difficulties or obstacles to modifying consumption; detection/referral episodes and requests for help for consumption problems; service utilization incidence; motivation for change and treatment; satisfaction or dissatisfaction with services consulted; reasons for stopping treatment or for non-utilization of services; and collaboration among network services. To meet our objectives, we then set about identifying emerging themes, based on the analyses, that centered on participants' experiences and, in relation to the phenomenological perspective, on their own interpretations of elements that influenced their initiating addiction treatment, that is, those that had an impact on all stages and which led them to get help from a health or criminal justice professional, or from a substance use support group.

\section{Results}


Concerning frequencies of alcohol and drug use, for example, 20 participants$57.1 \%$ of the total sample-including 14 from the criminal court, use cannabis three times or more per week. Cocaine and other stimulants seem to be more frequently used by individuals detected via the criminal court (i.e. respectively $34.8 \%$ and $30.4 \%$ of them use it three times or more per week) than individuals coming from other points of entry. Use of cannabis and alcohol seems to be more common for young adults from hospital emergencies. They are indeed nine- $81.8 \%$ of the subsample - to use cannabis at least one to three times per month, and ten to use alcohol at least 'less than once a month'. Table 2 displays full details concerning substance and alcohol frequencies of use, depending of the point of entry.

\section{(Insert Table 2)}

A majority of the participants present an exclusive drug use, notably cannabis, cocaine and other stimulants (62.9\% of the sample). Four participants (i.e. $11.4 \%)$ show a sole alcohol use. Lastly, nine young adults seem to have an associated alcohol and drug use (i.e. $25.7 \%$ of the sample). Specifically, according to the DEBAAlcool/Drogues terminology, $48.5 \%$ of the participants show at least a Low dependence of alcohol. In contrast, they are $68.6 \%$ to present a High dependence of drugs.

Among the entire sample, $31.4 \%$ of the participants $(n=11)$ reported one or less consultation in specialized addiction services during the last five years, mostly 
following the recent detection episode, despite long lasting alcohol and drug problems. A more exhaustive view of the data can be found in Table 3 .

\section{(Insert Table 3)}

The next section focuses on results from the thematic content analysis. Three components emerged from the analysis of young adults' experiences with access to services: personal elements linked to treatment initiation, such as personal motivation or expectations; the roles of immediate family members and peers; and influences of system characteristics, including health and social—as well as criminal justiceprofessionals.

\section{Personal Elements Linked to Treatment Initiation}

\section{Personal Motivation and Expectations}

Some participants demonstrate a firm will to stop using substances from the very beginning of treatment. The idea of changing their lives and feeling better is crucial to clearly formulating a request for help. Despite their young age, many participants talk about being genuinely exhausted, an outcome of the negative effects of early onset of, and heavy involvement with, substance abuse during adolescence.

I feel like changing everything... my lifestyle, myself, I want to find myself, get my self-esteem back, [...] because when I got here, I wasn't talking to anybody, 
I walked around with my head down, and... I was really a wreck... (Doris, 20) (Translation)

Sometimes initiation of treatment is precipitated by a life event that undermines their integrity or that of someone around them. At that point, they perceive that they "need to change", as opposed to previously, when they didn't "want to change".

When I got out of there [emergency department], I told myself that really, that was enough, $[\ldots]$... it's not that I want to change, now I have to change. That's really different. The doctors told me they'd never seen a 21 -year-old in this condition. (Edouard, 21) (Translation)

Another interesting element is that several young adults said they wanted to prove to the people close to them and to themselves that they can get through it. Their motivation to change were related to their perception that they have the capacity to reduce their substance use problems. The positive anticipation that they would be able to accomplish their goal also consolidated their sense of self-efficacy for related personal objectives.

I want to show that I can do it, that I can finish something. I never finished anything because I was high [...]. If I manage to get sober, I'll be able to succeed at other things when I'm sober [...] and then maybe do something with my life. (Ginette, 26) (Translation) 
Finally, for some people, the severity of the addiction to the substance can make them feel like they're out of control, which jeopardizes the process of asking for help despite their desire to stop using.

Yes, I always intended to change or stop, but I couldn't help it and so I kept

doing it. Because actually, I couldn't manage anything. (Frédéric, 28)

(Translation)

\section{Consumption and Ability to Control}

On the whole, participants' denial—or at least, the lack of perception-of substance use problems and lack of self-confidence in their capacity to change have a negative impact on seeking treatment.

First, a large majority of participants talked about prioritizing the pleasures and advantages of using.

It's... It's... It's so good! It's so bad! The really good aspects of drugs are the reason why I didn't go to get help. (Gino, 25) (Translation)

Then, some participants emphasize the idea of not having experienced negative consequences that are significant enough to justify changing. Thus they express a sort of denial, and tend to conceal or rationalize the scope of substance use.

And she asked me questions to find out if I was using too much, maybe it was a 
problem. But I always convinced myself, saying, "I... I have a social life, I work, I clean my house, I eat well enough, I'm not, I don't have problems... (Céline, 26) (Translation)

However, while other young adults are aware of the harmful nature of substance use, they still did not seek help. One person recalled being somewhat removed from his problem.

I didn't see that I had a problem, but I saw that my substance use was starting to cause problems. But it was like, how can I say that, it didn't affect me. (Alain, 22) (Translation)

Conversely, many participants stated being very confident that they could control themselves, they could stop on their own, using their own means.

Because I say to myself, if I want to stop getting high, I'll just stop. And if I want to stop drinking, I'll just stop. You just have to have the will. (Gino, 25) (Translation)

With the benefit of hindsight, some young adults said that their self-confidence might have been somewhat excessive and may have contributed to, for instance, their relapse.

I dropped out. This is what 'killed' me, to my mind, because I overestimated myself. I had an appointment every week [...]. I thought I was cured, then I 
overestimated myself and I did fail [...]. I felt a lot of shame, of guilt [...]. I told myself that I'd be able to control my [substance] use, that I had already worked hard on myself. (Alain, 22) (Translation)

As for the notion of stopping on their own, a few young people linked the idea of seeking outside help to acknowledging a form of weakness, admitting they were sick.

Going for help, it's like a form of weakness. [...] It's really rooted in my head that no matter what I do, if I need help to do it, it's because I'm not good enough to do it on my own. [...] It's really humiliating, not to be able to do it on your own. (Céline, 26) (Translation)

\section{Role of Relatives and Others in Treatment Initiation}

\section{Influences of Immediate Family}

An analysis of the data revealed that a young substance user's immediate family often has a positive effect on treatment initiation. In our sample, the term "immediate family" included parents, brothers or sisters, and spouses; it could also include other relatives (e.g. cousins), insofar as some young users were able to develop close emotional bonds with them.

First, parents and lovers are the ones who worry about heavy substance use. Occasionally some initiate the process and then present it to or impose it on the young user. Subsequently a few users tend to agree to make contact with health services, not 
for their own benefit, but first and foremost to please their relatives, redeem themselves and/or ease tensions.

Really, though, I went (to Treatment Centre A), I agreed to go, just for my parents. (Alain, 22) (Translation)

We also note that participants are committed to contacting a professional in response to a relative's or friend's distress or sadness. Guilt toward family, a lover or children are also sometimes used to justify and facilitate a request for help. More generally, having good family relations tends to encourage treatment initiation. Conversely, if family ties are severed - for instance, a young consumer is rejected by his parents - this can also lead to asking for care.

At the same time, you know that... even if it's not your decision, you know that your family, my mother, my sister, they really do love me [...]. Really, I was starting to see the problem and to think of myself, of my family. (Jocelyn, 24) (Translation)

Less often, some participants said they are afraid to seek care because of the reactions of the people around them. Acknowledging the problem is a source of family conflict or amplifies this conflict.

For my parents too. [...] So I said to myself that if I start detox, the result... it proves to my parents that I really have a problem. [...] as much as it made me 
feel better to tell myself it's okay, I'm in good hands, I'm doing what I have to do, I also knew that it freaks them out: their daughter, to have them ask how long has this been going on, right in front of our eyes? That this, and that... the tension it'll cause between them, and my little sister. (Barbara, 19) (Translation)

Most young adults perceive their parents as useful sources of information and support when they first start seeking treatment. In addition, some youth find it helpful when their relatives don't try to minimize the scope of their problems and accept the fact that he or she is using and the difficulties that come with substance use.

When it comes to my relatives and to the professionals at (Treatment Centre D) and at (Treatment Centre D1), [...], compassion, I think that was... I think that was the most helpful thing. The fact that people don't minimize the problem, that they empathize with the fact that something's going on and... The fact of not minimizing it, really, is to understand the problem, to show that yes, it's a problem. (Céline, 26) (Translation)

\section{Influences of Friends and Other People}

Aside from relatives, young adults also consider that friends and colleagues have an impact on seeking treatment. Most participants insist that being around other users makes it difficult to stop consumption, seek help and prevent relapses.

I happened to meet some friends once... friends! People with who I was using 
cocaine at the time. They looked like they were still using a lot. So, of course, I can't... I can't avoid them and pretend that I don't know them. (Alain, 23) (Translation)

On a more positive side, support from these peers is more specifically expressed through help finding quality therapy or a competent specialist. Initial referral can also originate in the prison system, through another inmate. This first step stage can then be a catalyst for a user to voluntarily and deliberately initiate treatment.

Having been able to keep working despite their substance abuse can sometimes go against young adults' initiating treatment. Some participants recall being afraid that their colleagues would find out about their substance use, which would lead to the former losing their jobs, especially if they worked in the health sector. Others prefer not having to explain their situation to employers or colleagues. In those cases, asking for help is perceived as harmful to a person's career.

That's a drag. Working in psychiatry, I could have had very good doctors, very good psychiatrists at (Hospital H) who are really well known, have really good reputations. But, of course, it made me a bit uncomfortable. [...] If you get fired from (Hospital H) because of substance use, it doesn't look too good on your $\mathrm{CV}$, that's for sure. [...] I didn't take any chances, despite the fact that for sure it's confidential, but at the same time, I told myself that... my colleagues will see that... (Bob, 29) (Translation) 


\title{
Impact of the Health and Criminal Justice Systems on Initiation of Substance
}

\author{
Abuse Treatment \\ Health and Criminal Justice Professionals
}

Health and criminal justice professionals whose jobs bring them into contact with young adults have a definite impact. Our sampling strategy of recruiting through criminal court enabled us to document the experiences of many participants who, despite their young age, had had repeated dealings with the criminal justice system. These delinquency trajectories should be considered concurrently with substance use trajectories and utilization of addiction services. In such contexts, some participants seem to greatly appreciate their relationships with their lawyers. A lawyer who simply mentions that it would be good to seek treatment has a significant impact on a user and ultimately plays a role in a user becoming aware that something is wrong and then in developing a therapeutic plan.

I took it to heart because I thought that a defense lawyer doesn't work for the good of his... of his clients, he works to defend his client, but also to make money. [...] I really took it seriously, like ... like an affirmation, a decision. I told myself, Ok. God, when it gets to the point that your defense lawyer tells you "Go get treatment, go get help..." (Bob, 29) (Translation)

Probation officers, who straddle both the health, social and criminal justice 
systems, are also very important to users. Participants understand that probation officers can guide them from prison to treatment and provide support. However, some young adults think that sometimes, probation officers complicate procedures more than facilitate them, or that their role is essentially correctional.

Just the fact that she calls me and leaves me a message... She didn't say, 'I'm gonna call the police! ». But she said to me, "Call me. Your mother called me... Blablabla.... Of course it proves that even though my officer, or, someone takes care of me and.... When I first got here, she called me and said, "I'm proud of you." And... that felt good. (Jocelyn, 24) (Translation)

Various health and other professionals can also play important roles, for all the young people in our sample. Participants think of the specialist and non-specialist physicians they see somewhat regularly as people they can trust. Users' perceptions of their family doctors are often positive, and consequently those professionals have positive impacts on users' acknowledging their problems as well as on guidance to the appropriate facilities.

Then yesterday, my doctor said, "Barbara, you're not admitting it but you really have a problem with substance use. It's not only psychologically that you're not well, so you use. And then when you use, you're not well. The point, really, is your substance use. You need to come to terms with it, to admit that you're not well." This is something I've always denied. [...] I think that it's time that I 
admit it. (Barbara, 18) (Translation)

Conversely, initial negative contacts with formal services adversely affect the desire to seek professional help. Some young adults emphasize the fact that the professional must suit them well. They focus on the person's being late or lacking respect for them. Other participants deplore a lack of knowledge, or judgments passed on people with addiction problems.

When I got there, my appointment was at 9. The psychiatrist arrived at 9:40! No apology. He sat there, all smug [...]. I sat down and looked at him: "I have nothing to say to you." I got up and I left. (Angele, 29) (Translation)

[...] It's terrible to be judged when you're looking to get help. [...] You need help, and then you're judged like that, it's ... it's really... It makes you want to leave and use, and you don't feel like going ... going elsewhere for help, you know? [...]. (Céline, 26) (Translation)

\section{Access to Substance Abuse Treatment Facilities and Interventions}

Two sets of components link access to substance abuse treatment facilities with addiction interventions: first, waiting times, whether or not they are linked to complex administrative procedures that must be followed; then, costs of access to care, an issue for many participants.

Waiting Times and Administrative Procedures 
Young adults perceive waiting times, especially preceding the first meeting with a substance abuse professional, as especially frustrating.

Really long. Because you've made up your mind and you have to wait... [...] So I find the waiting time super long. (Louis, 25) (Translation)

According to a few participants, procedure-particularly referrals and evaluations that must sometimes be done before accessing care-contributes to lengthening waiting times. Some participants are frustrated by these compulsory steps and simply give up and go back to using.

Yeah, I know all about paperwork [...], then, 6 months later, they call, and I said, "I've been waiting for 6 months. What's going on?" [...] She asked again for a doctor's paper so that I can be referred to a psychologist. [...] So it's more paperwork, I have to wait some more to see the doctor [...]. (Christopher, 25) (Translation)

Lack of Information and Costs for Services

A few participants also deplore the lack of information about substance abuse treatment facilities, or the fact that the information is not clear.

In the beginning, I didn't know that such service did exist nor where it was. Or anything else. When I arrived, everything was all new for me. (Adrien, 22) (Translation) 
The financial cost of substance abuse treatment does not appear to be particularly problematic for participants. Even if Canada's public healthcare system provides substance abuse treatment free of charge, a number of young adults referred to the ease of getting funding to access private facilities - typically residential facilitiesthrough social assistance or health insurance provided at their workplace.

I got treated at (Treatment Centre 4), [...] I had signed up for three months. I was working so the insurance paid. It didn't cost me anything. [...]. (Frederic, 27) (Translation)

A few participants insisted that some group insurance policies only cover a limited period of care, which restricts their choice of treatment, especially facilities in the private sector.

Of course it's offered through work, but the insurance only covers 21 to 28 days, which is really minimal. [...] I said to myself, "With the problem I've had, the years that I've been doing this, I'm sure that I need more than 28 days." (Bob, 29) (Translation)

However, several young adults expressed a need for psychological support to come to terms with their substance abuse problems, a service that is difficult to access in the public system and, for some, is much too expensive in the private sector 
she... she always referred me to psychologists which, at the time my salary was low, I was getting minimum wage, so I couldn't afford it... (Bob, 29) (Translation)

\section{Influence of Past Substance Abuse Treatment Experiences}

Finally, we found that young adults' past substance abuse treatment experiences can sometimes negatively influence the decision to initiate treatment again, when past experiences were unsatisfactory. Some participants' bad experiences with care in the past, whether general care or substance abuse treatment, has left them with a negative view of the usefulness of services or their capacity to successfully go through treatment. Those individuals express feelings of guilt and shame which, based on what they say, tend to drain their energy for seeking help, energy that is already difficult to muster.

[...] I've seen a lot of social workers, psychologists, psychiatrists in my life and honestly, it's never really done much. I'm a bit disillusioned with all that. I don't see the point. I don't see the point: each time I go, you tell them the same things every time, and there's absolutely no change. Nothing ever happens. [...] (Angèle, 30) (Translation)

However, repeating these inconclusive care experiences can also contribute to making some of these people aware that they have a substance use problem and that treatment really is useful. When young consumers finally get suitable treatment, their 
entire perception of the health care system can change. Experiencing real progress during treatment can make people more confident that treatment is a reliable and useful source of help.

Over time, I did learn how it [services] worked [...]. One of them really worked for me, it was the (Resource 9). I had every help that I needed. (Christopher, 25)

(Translation)

\section{Discussion}

The objective of this study was to investigate initiation of substance abuse treatment by young adults with substance abuse problems, using a phenomenological perspective. The contents of 62 semi-structured interviews conducted with 35 participants aged 18 to 30 living in Québec has enabled us to shed light on a set of elements that facilitate or hamper access to care. An initial result of particular interest is that facilitators and barriers for accessing services do not seem to occur concurrently during the process. Several factors likely take action at different moments, as it has already been noted by Gulliver, Griffiths, et Christensen (2010) on their literature review about mental health care access of adolescents and young adults.

Concerning our results, firstly, we notice that young adults seem to frequently struggle being conscious about risks of substance use. Sometimes, they are convinced they can deal with the problem on their own; and their abilities to perceive the need for 
care and to seek help are inadequate. Occasionally, they accurately identify the problem and their need for help, but then acceptability of treatment poses a problem, that is, seeking addiction services raises fears that this action may bring unwanted consequences, especially at work. Indeed, study participants occasionally expressed being afraid of how others see them. This raises the issue of users' accepting they have a disease and seeking treatment. Cunningham, Hodgins, Toneatto, and Cordingley (2009) present a similar finding in an adult population. Young adults may not want to initiate treatment because they do not want to confirm to their social environments that they are sick (Wisdom et al., 2011). Gulliver, Griffiths, and Christensen (2010) noted that fear of stigma was a predominant barrier in the mental health care access of adolescents and young adults. Furthermore, Choi et al. (2014) noticed that stigma impact was potentially more important for younger adults than for older adults, perhaps because of the emerging professional career. Finally, the fact that some participants of our sample present such fear about their professional activities is congruent with results from the review of Clement et al. (2015). This article indeed highlights that stigma impact even more young men working in health field.

Some comments paint a portrait of young adult users' feelings of invincibility regarding their substance use. Even though young users are aware rationally of the harmful nature of their consumption, some do not seek professional help. Although the phenomenon of remission without treatment among substance abusers cannot be denied 
(Authors, 2008; Klingemann, Sobell, \& Sobell, 2010), many participants themselves admit being too confident in their capacity to self-regulate and overcome their problem, which hinders their actions toward seeking professional help. This confidence could be linked to fears of self-stigma (Drapalski et al., 2013). We can also hypothesize that the idea of accepting external assistance or treatment goes against those feelings of invincibility (Barry, Pickard, \& Ansel, 2009; Wickman, Anderson, \& Smith Greenberg, 2008) and can damage self-esteem (Drapalski et al., 2013) of young people-who can easily feel shame or culpability. Major role of personal beliefs as treatment barriers has already been noticed in the literature (see the review of Priester et al., 2016). It gathers beliefs about healthcare services, professionals, cultural beliefs, or beliefs of stigma on substance users.

This first part highlighted personal factors. However, considering how challenging is the transitional age constituted by the end of adolescence and the beginning of adulthood, other factors can intervene. Environmental factors-associated with family or peers - and institutional factors (i.e. healthcare system characteristics, appropriate interventions, etc.) need to be taken into account (Bukstein, Cornelius, Trunzo, Kelly, \& Wood, 2005). Indeed, those factors can affect personal perceptions and beliefs about health (Leslie et al., 2015). Moreover, in their study, van der Pol et al. (2013) note that patients in treatment for substance abuse are very aware of the support they get from relatives. Conversely, in our sample, users who reported low motivation 
to seek treatment during their addiction trajectory perceive mostly pressure from people around them. The important but sometimes nuanced role of friends and family is evident. As seen in the literature, the influence of friends and family is very beneficial at different stages of treatment access: for instance, a friend or relative can initiate the process, seek information and accompany the user to a treatment facility. However, if a user feels too much social pressure, treatment engagement can be adversely affected. Goodman, Peterson-Badali, and Henderson (2011) indicate that the greater the pressure, the more the user risks accepting treatment only in response to that pressure. However, families of young adults are important to treatment access, and families' mostly facilitating roles should be highlighted. Family involvement in substance abuse treatment for adolescents is a long-accepted best practice (Authors, 2006; Center for Substance Abuse Treatment, 1999; Waldron \& Kaminer, 2004) and its importance in the lives of young adults should not be neglected.

Health and social services - as well as criminal justice-professionals play special roles in young adults' access to treatment. As key stakeholders and trustworthy experts, they can contribute to raising awareness about the need for treatment and seeking help. In addition to the expertise provided, relations with those professionals can foster or hinder young substance users' access to treatment (Gogel et al., 2010). In our sample, they seem to be a pertinent resource for individuals in connection with criminal system, whether or not sentenced to a jail term. Meyer, Tangney, Stuewig, and 
Moore (2014) noted that it's a population particularly at risk, expressing multiple needs. However, in their study, only $18.5 \%$ of inmates with a problematic substance use follow a specialized treatment. Their participants insist on the fact that they won't stay enough time in jail to follow in good conditions a treatment, that they don't believe in the treatment efficacy, or that they fear an amplified stigma.

Certain characteristics of the health system, such as waiting times, administrative procedures, lack of information, and costs have an impact on initiation of substance abuse treatment. These elements define treatment accessibility and affordability (Levesque et al., 2013). For Saunders et al. (2006), they are external barriers that restrict users' access to treatment. Waiting time is a significant barrier for young substance users seeking treatment, especially when their request for help presents a certain urgency. Waiting times and multi-step procedures that delay onset of treatment can be crippling, as several studies on adult and adolescent populations in the literature note (Grella, Gil-Rivas, \& Cooper, 2004; Redko, Rapp, \& Carlson, 2006; Wisdom et al., 2011). However, unlike other studies (Perron et al., 2009; Probst, Manthey, Martinez, \& Rehm, 2015; Rockloff \& Schofield, 2004; Wu et al., 2011), the issue of cost is fairly marginal here. This result is noteworthy given that, even if in Canada, substance abuse treatment in the public sector is free, major issues with its access may leave drug users and their families spending a lot of money on private addiction facilities. Limits of health insurance coverage (i.e. number of sessions, treatment duration) will have a 
negative impact on healthcare access (Sterling et al., 2010). Direct and indirect costs can remain a limiting factor for disadvantage populations-homeless or with justice issues - like some participants of our sample (Adler et al., 2015; Godley et al., 2000).

In a context of multiple use of substance abuse treatment services, data analysis highlights the fact that making a decision to get help for substance abuse problems is notably facilitated or hindered by prior significant care experiences. Substance abuse treatment is often an iterative process (Naughton, Alexandrou, Dryden, Bath, \& Giles, 2013), even for young adults. Indeed, several participants of the sample already had a history of treatment for their alcohol or drug use. As it has already been seen elsewhere, if past experiences have been especially negative, young adults will not want to seek and/or enter into treatment again (Wisdom et al., 2011). Conversely, positive past experiences and good relations with staff encourage users to obtain professional help again (Authors, 2015; Gulliver et al., 2010; Saunders et al., 2006; van der Pol et al., 2013). Providing treatment that meets the needs of young adults is especially important because of the influence it will have on their desire seek help in the future.

This study looks at initiation of substance abuse treatment by young adults in Québec (Canada) from a phenomenological perspective. A set of interesting elements place access to substance abuse treatment at a crossroads of various trajectories. Such a personal journey sometimes requires a person to move beyond some firmly anchored beliefs to become aware of difficulties and acknowledge the need for help. However, an 
explanation only based on personal factors can't be totally appropriate, since young people's friends and family also significantly influence addiction and service trajectories. Young adults can be particularly marked by the absence of or inconsistent support of friends and family members. Finally, treatment initiation is also shaped by trajectory of health and social service utilization as well as relations with professionals. Engaging in trusting relationships with health professionals is part of a complex developmental process that requires young participants, who seek autonomy, to accept that they need help. Those are all elements that professionals can address to better support youth who are struggling with substance abuse.

Inasmuch as access to care is particularly tenuous for young adults, it is necessary to develop tailored health practices (Sterling et al., 2010) focused on the very specific needs of this population. If the traditional approach is not quite compatible with the desire to change expressed by some young substance users, it may be advisable to develop and offer some tools to help reinforcing with self-control, self-reliance, selfefficacy abilities, and to provide programs that reduce stigma associated with drug abuse and help-seeking behavior by improving mental health literacy (Gulliver et al., 2010; Kelly, Urbanoski, Hoeppner, \& Slaymaker, 2012). Some young adults may be ready to change, but don't have the means to do it. To facilitate their access to a professional help, new ways - highly personalized - of information, prevention and treatment integrating emerging technologies should be designed (e.g. computerized 
cognitive behavior therapy (Musiat \& Tarrier, 2014); text messaging/mobile applications interventions (Mason, Ola, Zaharakis, \& Zhang, 2015)). As seen in the literature, people may prefer online help when they face too many "external" barriers to traditional treatment (Townsend \& Gearing, 2011). These solutions could contribute to promote help-seeking behaviors and to decrease belief and fear of stigma (Burns, Durkin, \& Nicholas, 2009). Working on reducing delays may need pre-interventions to help before admission in a more formal structure or appointments (Grella et al., 2004; Johnson et al., 2015). At another level, the help of various stakeholders (e.g. trusted physicians, close relations) should be enlisted to create and sustain connections. Finally, for young adults whose working conditions are precarious, improving access to confidential substance abuse treatment in professional settings is important.

This study has some limitations. First, one may notice that the saturation criterion doesn't seem to be fulfilled on, for instance, points of entry or recruitment area subsamples, according to their respective sizes. In qualitative data analysis, it is as important to have a diversified sample as to achieve saturation according to criteria deemed pertinent. Moreover, it would have been useful for our analysis to compare the views of young adults based on their point of entry into care. The pathway to treatment — and perception of the pathway — of users who have often interacted with the justice system may differ from that of users engaging in treatment for the very first time. However, it wasn't the main objective of this research and the heterogeneous 
distribution of the sample on the different points of entry (i.e. 23 individuals come from the criminal court versus 11 from hospital emergency rooms, and only one come from a HSSC) didn't seem appropriate to make meaningful comparisons. Other sociodemographic characteristics could also have been used as filters for comparison, e.g., geographical location, gender (Wu et al., 2011), as well as comparing these data with data from older adults on the larger sample.

Concerning the strengths of this work, a pertinent point to retain is sample selection of young substance users, which was derived from a larger sample from Research Alliance Program. Although the question of access to substance abuse treatment is central, it is also important to look at the specific characteristics of the youngest users (Bukstein et al., 2005; Evans et al., 2013; Gulliver et al., 2010; Hoeppner et al., 2014; Parthasarathy \& Weisner, 2005; Priester et al., 2016; SchumanOlivier et al., 2014; Smith et al., 2011; Sterling et al., 2010). While older individuals may have more experience with services, fruitful or not, young users are often still unfamiliar with these settings; they can then express specific needs which, if they are met, will influence their treatment access experiences.

In terms of the analysis, using a phenomenological perspective based on the views of young participants allows for sensitive interpretation of sometimes complex processes based on how individuals feel and what they have experienced. One factor, whether it is an individual, environmental or institutional one, may act as barrier for 
some persons, and as facilitators for others (Naughton et al., 2013). It depends on the cultural context and on the healthcare system too (Probst et al., 2015). Lastly, Gulliver et al. (2010) reassert that those factors can impact the process of care at different moments. Such enhanced knowledge makes it possible to propose interventions more closely tailored to the needs expressed by the participants.

\section{Acknowledgements}

We would like to acknowledge the $\mathrm{X}$ of the $\mathrm{X}$ at the $\mathrm{X}$ and every partners of the $\mathrm{X}$. We also thank all members of the research team, health and social services professionals and users from the participating sites.

\section{Funding}

This study was funded by the $\mathrm{X}$ and Universite $\mathrm{X}$. $\mathrm{X}$ provided funding for translation of the article into English.

\section{Declaration of conflicting interests}

The authors declare that there is no conflict of interest.

\section{References}

Adler, G., Pritchett, L. R., Kauth, M. R., \& Mott, J. (2015). Staff perceptions of homeless veterans' needs and available services at community-based outpatient 
clinics. Journal of Rural Mental Health, 39(1), 46-53. http://doi.org/10.1037/rmh0000024

Andersen, R. M. (1995). Revisiting the behavioral model and access to medical care: Does it matter? Journal of Health and Social Behavior, 36(1), 1-10. http://doi.org/10.2307/2137284

Arnett, J. J. (2000). Emerging adulthood. A theory of development from the late teens through the twenties. The American Psychologist, 55(5), 469-480. http://doi.org/10.1037/0003-066X.55.5.469

Authors (2006). Details omitted for double-blind reviewing.

Authors (2008). Details omitted for double-blind reviewing.

Authors (2009). Details omitted for double-blind reviewing.

Authors (2014). Details omitted for double-blind reviewing.

Authors (2015). Details omitted for double-blind reviewing.

Barry, C. T., Pickard, J. D., \& Ansel, L. L. (2009). The associations of adolescent invulnerability and narcissism with problem behaviors. Personality and Individual

Differences, $47(6)$,

577-582.

http://doi.org/10.1016/j.paid.2009.05.022

Beaujot, R., \& Kerr, D. (2007). Emerging youth transition patterns in Canada: Opportunities and risks. PSC Discussion Papers Series, 21(5), 1. 
Bloor, M., \& Wood, F. (2006). Keywords in qualitative methods: A vocabulary of research concepts. London: Sage.

Bukstein, O. G., Cornelius, J., Trunzo, A. C., Kelly, T. M., \& Wood, D. S. (2005). Clinical predictors of treatment in a population of adolescents with alcohol use disorders. $\quad$ Addictive $\quad$ Behaviors, $\quad 30(9), \quad$ 1663-1673. http://doi.org/10.1016/j.addbeh.2005.07.013

Burns, J. M., Durkin, L. A., \& Nicholas, J. (2009). Mental health of young people in the United States: what role can the internet play in reducing stigma and promoting help seeking? The Journal of Adolescent Health: Official Publication of the Society for Adolescent Medicine, 45(1), 95-97. http://doi.org/10.1016/j.jadohealth.2008.12.006

Center for Substance Abuse Treatment. (1999). Treatment of Adolescents with Substance Use Disorders. Rockville (MD): Substance Abuse and Mental Health Services Administration (US). Consulté à l'adresse http://www.ncbi.nlm.nih.gov/books/NBK64350/

Choi, N. G., DiNitto, D. M., \& Marti, C. N. (2014). Treatment use, perceived need, and barriers to seeking treatment for substance abuse and mental health problems among older adults compared to younger adults. Drug and Alcohol Dependence, 145, 113-120. http://doi.org/10.1016/j.drugalcdep.2014.10.004 
Clement, S., Schauman, O., Graham, T., Maggioni, F., Evans-Lacko, S., Bezborodovs, N., ... Thornicroft, G. (2015). What is the impact of mental health-related stigma on help-seeking? A systematic review of quantitative and qualitative studies. Psychological $\quad$ Medicine, $\quad 45(1), \quad$ 11-27. http://doi.org/10.1017/S0033291714000129

Cunningham, J. A., Hodgins, D., Toneatto, T., \& Cordingley, J. (2009). Barriers to treatment for problem gamblers in Ontario. Toronto, Canada: Ontario Problem Gambling Research Centre.

Drapalski, A. L., Lucksted, A., Perrin, P. B., Aakre, J. M., Brown, C. H., DeForge, B. R., \& Boyd, J. E. (2013). A model of internalized stigma and its effects on people with mental illness. Psychiatric Services, 64(3), 264-269. http://doi.org/10.1176/appi.ps.001322012

Evans, E., Li, L., Grella, C., Brecht, M.-L., \& Hser, Y.-I. (2013). Developmental timing of first drug treatment and 10-year patterns of drug use. Journal of Substance Abuse Treatment, 44(3), 271-279. http://doi.org/10.1016/j.jsat.2012.07.012

Giorgi, A. (2005). The phenomenological movement and research in the human sciences. Nursing Science Quarterly, 18(1), 75-82. http://doi.org/10.1177/0894318404272112 
Godley, S. H., Finch, M., Dougan, L., McDonnell, M., McDermeit, M., \& Carey, A. (2000). Case management for dually diagnosed individuals involved in the criminal justice system. Journal of Substance Abuse Treatment, 18(2), 137-148.

Gogel, L. P., Cavaleri, M. A., Gardin, J. G., \& Wisdom, J. P. (2010). Retention and ongoing participation in residential substance abuse treatment: Perspectives from adolescents, parents and staff on the treatment process. The Journal of Behavioral Health Services \& Research, 38(4), 488-496. http://doi.org/10.1007/s11414-010-9226-7

Goodman, I., Peterson-Badali, M., \& Henderson, J. (2011). Understanding motivation for substance use treatment: The role of social pressure during the transition to adulthood. Addictive Behaviors, 36(6), 660-668. http://doi.org/10.1016/j.addbeh.2011.01.011

Gossop, M., Darke, S., Griffiths, P., Hando, J., Powis, B., Hall, W., \& Strang, J. (1995). The Severity of Dependence Scale (SDS): psychometric properties of the SDS in English and Australian samples of heroin, cocaine and amphetamine users. Addiction, 90(5), 607-614. http://doi.org/10.1111/j.1360-0443.1995.tb02199.x

Grella, C. E., Gil-Rivas, V., \& Cooper, L. (2004). Perceptions of mental health and substance abuse program administrators and staff on service delivery to persons with co-occurring substance abuse and mental disorders. The Journal of Behavioral Health Services \& Research, 31(1), 38-49. 
Gulliver, A., Griffiths, K. M., \& Christensen, H. (2010). Perceived barriers and facilitators to mental health help-seeking in young people: a systematic review. BMC Psychiatry, 10, 113. http://doi.org/10.1186/1471-244X-10-113

Hawkins, E. H. (2009). A tale of two systems: co-occurring mental health and substance abuse disorders treatment for adolescents. Annual Review of Psychology, 60, 197-227. http://doi.org/10.1146/annurev.psych.60.110707.163456

Hoeppner, B. B., Hoeppner, S. S., \& Kelly, J. F. (2014). Do young people benefit from AA as much, and in the same ways, as adult aged 30+? A moderated multiple mediation analysis. Drug and Alcohol Dependence, 143, 181-188. http://doi.org/10.1016/j.drugalcdep.2014.07.023

Johnson, J. E., Schonbrun, Y. C., Peabody, M. E., Shefner, R. T., Fernandes, K. M., Rosen, R. K., \& Zlotnick, C. (2015). Provider experiences with prison care and aftercare for women with co-occurring mental health and substance use disorders: Treatment, resource, and systems integration challenges. The Journal of Behavioral Health Services \& Research, 42(4), 417-436. http://doi.org/10.1007/s11414-014-9397-8

Kelly, J. F., Urbanoski, K. A., Hoeppner, B. B., \& Slaymaker, V. (2012). «Ready, willing, and (not) able » to change: young adults' response to residential treatment. Drug and Alcohol Dependence, 121(3), 224-230. http://doi.org/10.1016/j.drugalcdep.2011.09.003 
Klingemann, H., Sobell, M. B., \& Sobell, L. C. (2010). Continuities and changes in selfchange research. Addiction (Abingdon, England), 105(9), 1510-1518. http://doi.org/10.1111/j.1360-0443.2009.02770.x

Leslie, K. (2008). Youth substance use and abuse: challenges and strategies for identification and intervention. CMAJ: Canadian Medical Association Journal = Journal de l'Association Medicale Canadienne, 178(2), 145-148. http://doi.org/10.1503/cmaj.071410

Leslie, K., Manning, S. J., Maser, C., Snelgrove, D., Thornton, T., Wills, A., \& Brands, B. (2015). Long-Term Health and Psychosocial Status of Youth Who Received Substance Abuse Treatment in Adolescence. International Journal of Mental Health and Addiction, 1-9. http://doi.org/10.1007/s11469-015-9585-7

Levesque, J.-F., Harris, M. F., \& Russell, G. (2013). Patient-centred access to health care: Conceptualising access at the interface of health systems and populations. International Journal for Equity in Health, 12(1), 18. http://doi.org/10.1186/1475-9276-12-18

Mason, M., Ola, B., Zaharakis, N., \& Zhang, J. (2015). Text messaging interventions for adolescent and young adult substance use: a meta-analysis. Prevention Science: The Official Journal of the Society for Prevention Research, 16(2), 181-188. http://doi.org/10.1007/s11121-014-0498-7 
Meyer, C. L., Tangney, J. P., Stuewig, J., \& Moore, K. E. (2014). Why Do Some Jail Inmates Not Engage in Treatment and Services? International Journal of Offender Therapy and Comparative Criminology, 58(8), 914-930. http://doi.org/10.1177/0306624X13489828

Miles, M.-B., \& Huberman, A.-M. (2003). Analyse des données qualitatives (2ème édition). Paris: De Boeck.

Musiat, P., \& Tarrier, N. (2014). Collateral outcomes in e-mental health: a systematic review of the evidence for added benefits of computerized cognitive behavior therapy interventions for mental health. Psychological Medicine, 44(15), 31373150. http://doi.org/10.1017/S0033291714000245

Naughton, F., Alexandrou, E., Dryden, S., Bath, J., \& Giles, M. (2013). Understanding treatment delay among problem drinkers: What inhibits and facilitates helpseeking? Drugs: Education, Prevention and Policy, 20(4), 297-303. http://doi.org/10.3109/09687637.2012.745121

Orford, J. (2008). Asking the right questions in the right way: the need for a shift in research on psychological treatments for addiction. Addiction (Abingdon, England), 103(6), 875-885; discussion 886-892. http://doi.org/10.1111/j.13600443.2007.02092.x

Paillé, P., \& Mucchielli, A. (2003). L'analyse qualitative en sciences humaines et sociales. Paris: Armand Collin. 
Parthasarathy, S., \& Weisner, C. M. (2005). Five-year trajectories of health care utilization and cost in a drug and alcohol treatment sample. Drug and Alcohol Dependence, 80(2), 231-240. http://doi.org/10.1016/j.drugalcdep.2005.04.004

Pearson, C., Janz, T., \& Ali, J. (2013). Mental and substance use disorders in Canada (No. Catalogue no. 82-624-X). Ottawa, Ontario: Statistique Canada.

Perron, B. E., Mowbray, O. P., Glass, J. E., Delva, J., Vaughn, M. G., \& Howard, M. (2009). Differences in service utilization and barriers among Blacks, Hispanics, and Whites with drug use disorders. Substance Abuse Treatment, Prevention, and Policy, 4(1), 3. http://doi.org/10.1186/1747-597X-4-3

Pescosolido, B. A., Gardner, C. B., \& Lubell, K. M. (1998). How people get into mental health services: Stories of choice, coercion and «muddling through » from «first-timers ». Social Science \& Medicine, 46(2), 275-286. http://doi.org/10.1016/S0277-9536(97)00160-3

Priester, M. A., Browne, T., Iachini, A., Clone, S., DeHart, D., \& Seay, K. D. (2016). Treatment access barriers and disparities among individuals with co-occurring mental health and substance use disorders: An integrative literature review. Journal of Substance Abuse Treatment, 61, 47-59. http://doi.org/10.1016/j.jsat.2015.09.006

Probst, C., Manthey, J., Martinez, A., \& Rehm, J. (2015). Alcohol use disorder severity and reported reasons not to seek treatment: a cross-sectional study in European 
primary care practices. Substance Abuse Treatment, Prevention, and Policy, 10, 32. http://doi.org/10.1186/s13011-015-0028-z

Prochaska, J. O., DiClemente, C. C., \& Norcross, J. C. (1992). In search of how people change: Applications to addictive behaviors. American Psychologist, 47(9), 1102-1114. http://doi.org/10.1037/0003-066X.47.9.1102

Raistrick, D., Dunbar, G., \& Davidson, R. (1983). Development of a questionnaire to measure Alcohol Dependence. British Journal of Addiction, 78(1), 89-95. http://doi.org/10.1111/j.1360-0443.1983.tb02484.x

Redko, C., Rapp, R. C., \& Carlson, R. G. (2006). Waiting time as a barrier to treatment entry: Perceptions of substance users. Journal of Drug Issues, 36(4), 831-852. http://doi.org/10.1177/002204260603600404

Rockloff, M. J., \& Schofield, G. (2004). Factor analysis of barriers to treatment for problem gambling. Journal of Gambling Studies, 20(2), 121-126. http://doi.org/10.1023/B:JOGS.0000022305.01606.da

Rotondi, N. K., \& Rush, B. (2012). Monitoring utilization of a large scale addiction treatment system: the Drug and Alcohol Treatment Information System (DATIS). Substance Abuse: Research and Treatment, 6, 73-84. http://doi.org/10.4137/SART.S9617 
Saunders, S. M., Zygowicz, K. M., \& D’Angelo, B. R. (2006). Person-related and treatment-related barriers to alcohol treatment. Journal of Substance Abuse Treatment, 30(3), 261-270. http://doi.org/doi:10.1016/j.jsat.2006.01.003

Schuman-Olivier, Z., Weiss, R. D., Hoeppner, B. B., Borodovsky, J., \& Albanese, M. J. (2014). Emerging adult age status predicts poor buprenorphine treatment retention. Journal of Substance Abuse Treatment, 47(3), 202-212. http://doi.org/10.1016/j.jsat.2014.04.006

Smith, D. C., Godley, S. H., Godley, M. D., \& Dennis, M. L. (2011). Adolescent Community Reinforcement Approach (A-CRA) Outcomes Differ among Emerging Adults and Adolescents. Journal of substance abuse treatment, 41(4), 422-430. http://doi.org/10.1016/j.jsat.2011.06.003

Sterling, S., Weisner, C., Hinman, A., \& Parthasarathy, S. (2010). Access to treatment for adolescents with substance use and co-occurring disorders: challenges and opportunities. Journal of the American Academy of Child and Adolescent Psychiatry, 49(7), 637-726. http://doi.org/10.1016/j.jaac.2010.03.019

Townsend, L., \& Gearing, R. (2011). P03-163 - The influence of health beliefs and social stigma on choice of internet support groups over formal mental health services. European Psychiatry, 26, Supplement 1, 1332. http://doi.org/10.1016/S0924-9338(11)73037-1 
Tremblay, J., Rouillard, P., \& Sirois, M. (2004). Manuel d'utilisation du Dépistage et Évaluation du Besoin d'Aide-Alcool/Drogues (DÉBA-A/D). Québec: Service de recherche CRUV/ALTO.

United Nations. (2014). World Drug Report 2014. Austria, Vienna: United Nations Office on Drugs and Crime.

van der Pol, P., Liebregts, N., de Graaf, R., Korf, D. J., van den Brink, W., \& van Laar, M. (2013). Facilitators and barriers in treatment seeking for cannabis dependence. Drug and Alcohol Dependence, 133(2), 776-780. http://doi.org/10.1016/j.drugalcdep.2013.08.011

Waldron, H. B., \& Kaminer, Y. (2004). On the learning curve: the emerging evidence supporting cognitive-behavioral therapies for adolescent substance abuse. Addiction, 99, 93-105. http://doi.org/10.1111/j.1360-0443.2004.00857.x

Wickman, M. E., Anderson, N. L. R., \& Smith Greenberg, C. (2008). The Adolescent Perception of Invincibility and Its Influence on Teen Acceptance of Health Promotion Strategies. Journal of Pediatric Nursing, 23(6), 460-468. http://doi.org/10.1016/j.pedn.2008.02.003

Wisdom, J. P., Cavaleri, M., Gogel, L., \& Nacht, M. (2011). Barriers and facilitators to adolescent drug treatment: Youth, family, and staff reports. Addiction Research \& Theory, 19(2), 179-188. http://doi.org/10.3109/16066359.2010.530711 
Wu, L.-T., Blazer, D. G., Li, T.-K., \& Woody, G. E. (2011). Treatment use and barriers among adolescents with prescription opioid use disorders. Addictive Behaviors, 36(12), 1233-1239. http://doi.org/10.1016/j.addbeh.2011.07.033

Xu, J., Rapp, R. C., Wang, J., \& Carlson, R. G. (2008). The multidimensional structure of external barriers to substance abuse treatment and its invariance across gender, ethnicity, and age. Substance Abuse, 29(1), 43-54. http://doi.org/10.1300/J465v29n01_06 
Table 1

Sociodemographic Characteristics of the Sample

\begin{tabular}{|c|c|c|c|c|}
\hline Variable & $M$ & $E C$ & Min & Max \\
\hline $\operatorname{Age}^{\mathrm{a}}$ & 24.68 & 3.44 & 18 & 30 \\
\hline Variables & & & $n$ & $\%$ \\
\hline \multicolumn{5}{|l|}{ Sex } \\
\hline Male & & & 26 & 74.3 \\
\hline Female & & & 9 & 25.7 \\
\hline \multicolumn{5}{|l|}{ Recruitment area } \\
\hline Montréal & & & 17 & 48.6 \\
\hline Mauricie-Centre-du-Québec & & & 18 & 51.4 \\
\hline \multicolumn{5}{|l|}{ Points of entry } \\
\hline Criminal justice system & & & 23 & 65.7 \\
\hline Hospital emergency rooms & & & 11 & 31.4 \\
\hline Health and Social Services Centers (HSSC) & & & 1 & 2.9 \\
\hline \multicolumn{5}{|l|}{ Marital status } \\
\hline Married & & & 1 & 2.9 \\
\hline Common-law spouse or domestic partnership & & & 11 & 31.4 \\
\hline Single & & & 23 & 65.7 \\
\hline \multicolumn{5}{|l|}{ Highest level of education completed } \\
\hline Elementary & & & 17 & 48.6 \\
\hline High school (general) & & & 11 & 31.4 \\
\hline High school (vocational) & & & 1 & 2.9 \\
\hline College & & & 4 & 11.4 \\
\hline University & & & 2 & 5.7 \\
\hline \multicolumn{5}{|l|}{ Annual personal income ${ }^{a}$} \\
\hline Less than CAN\$11999 & & & 20 & 58.8 \\
\hline CAN\$12 000 to CAN\$39999 & & & 10 & 29.4 \\
\hline CAN\$40 000 or over & & & 4 & 11.4 \\
\hline \multicolumn{5}{|l|}{ Children } \\
\hline 0 & & & 25 & 71.4 \\
\hline 1 or more & & & 10 & 28.6 \\
\hline
\end{tabular}

Note. $N=35$

${ }^{\mathrm{a}} n=34$. 
Table 2

Sample Frequencies of Substance Use depending on the Point of Entry

\begin{tabular}{|c|c|c|c|c|c|c|c|c|}
\hline \multirow{3}{*}{$\begin{array}{l}\text { During the last } 12 \text { months, how often did you use } \\
\ldots\end{array}$} & \multicolumn{8}{|c|}{ Points of entry } \\
\hline & \multicolumn{2}{|c|}{$\begin{array}{l}\text { Criminal } \\
\text { justice } \\
\text { system }\end{array}$} & \multicolumn{2}{|c|}{$\begin{array}{l}\text { Hospital } \\
\text { emergency } \\
\text { rooms }\end{array}$} & \multicolumn{2}{|c|}{$\begin{array}{c}\text { Health } \\
\text { and } \\
\text { Social } \\
\text { Services } \\
\text { Centers }\end{array}$} & \multicolumn{2}{|c|}{ Total } \\
\hline & $n$ & $\%$ & $n$ & $\%$ & $n$ & $\%$ & $n$ & $\%$ \\
\hline \multicolumn{9}{|l|}{ Alcohol } \\
\hline Never & 2 & 9.1 & 1 & 9.1 & 0 & 0.0 & 3 & 8.8 \\
\hline Less than once a month & 7 & 31.8 & 2 & 18.2 & 0 & 0.0 & 9 & 26.5 \\
\hline One to three times per month & 5 & 22.7 & 1 & 9.1 & 0 & 0.0 & 6 & 17.6 \\
\hline Weekly or semi-weekly & 3 & 13.6 & 2 & 18.2 & 0 & 0.0 & 5 & 14.7 \\
\hline Three times or more per week & 5 & 22.7 & 5 & 45.5 & 1 & 100.0 & 11 & 32.4 \\
\hline Total & 22 & 100.0 & 11 & 100.0 & 1 & 100.0 & $34^{\mathrm{a}}$ & 100.0 \\
\hline \multicolumn{9}{|l|}{ Sedatives } \\
\hline Never & 13 & 56.5 & 9 & 81.8 & 1 & 100.0 & 23 & 65.7 \\
\hline Less than once a month & 2 & 8.7 & 1 & 9.1 & 0 & 0.0 & 3 & 8.6 \\
\hline One to three times per month & 3 & 13.0 & 0 & 0.0 & 0 & 0.0 & 3 & 8.6 \\
\hline Weekly or semi-weekly & 2 & 8.7 & 1 & 9.1 & 0 & 0.0 & 3 & 8.6 \\
\hline Three times or more per week & 3 & 13.0 & 0 & 0.0 & 0 & 0.0 & 3 & 8.6 \\
\hline Total & 23 & 100.0 & 11 & 100.0 & 1 & 100.0 & 35 & 100.0 \\
\hline \multicolumn{9}{|l|}{ Cannabis } \\
\hline Never & 2 & 8.7 & 2 & 18.2 & 0 & 0.0 & 4 & 11.4 \\
\hline One to three times per month & 3 & 13.0 & 1 & 9.1 & 0 & 0.0 & 4 & 11.4 \\
\hline Weekly or semi-weekly & 4 & 17.4 & 2 & 18.2 & 1 & 100.0 & 7 & 20.0 \\
\hline Three times or more per week & 14 & 60.9 & 6 & 54.5 & 0 & 0.0 & 20 & 57.1 \\
\hline Total & 23 & 100.0 & 11 & 100.0 & 1 & 100.0 & 35 & 100.0 \\
\hline \multicolumn{9}{|l|}{ PCP } \\
\hline Never & 18 & 78.3 & 11 & 100.0 & 1 & 100.0 & 30 & 85.7 \\
\hline Less than once a month & 1 & 4.3 & 0 & 0.0 & 0 & 0.0 & 1 & 2.9 \\
\hline One to three times per month & 1 & 4.3 & 0 & 0.0 & 0 & 0.0 & 1 & 2.9 \\
\hline Weekly or semi-weekly & 1 & 4.3 & 0 & 0.0 & 0 & 0.0 & 1 & 2.9 \\
\hline Three times or more per week & 2 & 8.7 & 0 & 0.0 & 0 & 0.0 & 2 & 5.7 \\
\hline Total & 23 & 100.0 & 11 & 100.0 & 1 & 100.0 & 35 & 100.0 \\
\hline \multicolumn{9}{|l|}{ Hallucinogens } \\
\hline Never & 11 & 47.8 & 11 & 100.0 & 1 & 100.0 & 23 & 65.7 \\
\hline Less than once a month & 7 & 30.4 & 0 & 0.0 & 0 & 0.0 & 7 & 20.0 \\
\hline One to three times per month & 2 & 8.7 & 0 & 0.0 & 0 & 0.0 & 2 & 5.7 \\
\hline Weekly or semi-weekly & 1 & 4.3 & 0 & 0.0 & 0 & 0.0 & 1 & 2.9 \\
\hline Three times or more per week & 2 & 8.7 & 0 & 0.0 & 0 & 0.0 & 2 & 5.7 \\
\hline Total & 23 & 100.0 & 11 & 100.0 & 1 & 100.0 & 35 & 100.0 \\
\hline \multicolumn{9}{|l|}{ Cocaine } \\
\hline Never & 5 & 21.7 & 9 & 81.8 & 0 & 0.0 & 14 & 40.0 \\
\hline Less than once a month & 6 & 26.1 & 0 & 0.0 & 1 & 100.0 & 7 & 20.0 \\
\hline
\end{tabular}


One to three times per month Weekly or semi-weekly

Three times or more per week Total

Other stimulants (excepting cocaine)

Never

Less than once a month

One to three times per month

Weekly or semi-weekly

Three times or more per week

Total

Opiates

Never

Less than once a month

One to three times per month

Weekly or semi-weekly

Three times or more per week

Total

Inhalants

Never

Less than once a month

Total

\begin{tabular}{cccccccc}
2 & 8.7 & 1 & 9.1 & 0 & 0.0 & 3 & 8.6 \\
2 & 8.7 & 1 & 9.1 & 0 & 0.0 & 3 & 8.6 \\
8 & 34.8 & 0 & 0.0 & 0 & 0.0 & 8 & 22.9 \\
23 & 100.0 & 11 & 100.0 & 1 & 100.0 & 35 & 100.0 \\
& & & & & & & \\
7 & 30.4 & 6 & 54.5 & 1 & 100.0 & 14 & 40.0 \\
7 & 30.4 & 0 & 0.0 & 0 & 0.0 & 7 & 20.0 \\
1 & 4.3 & 2 & 18.2 & 0 & 0.0 & 3 & 8.6 \\
1 & 4.3 & 2 & 18.2 & 0 & 0.0 & 3 & 8.6 \\
7 & 30.4 & 1 & 9.1 & 0 & 0.0 & 8 & 22.9 \\
23 & 100.0 & 11 & 100.0 & 1 & 100.0 & 35 & 100.0 \\
& & & & & & & \\
15 & 65.2 & 10 & 90.9 & 1 & 100.0 & 26 & 74.3 \\
1 & 4.3 & 0 & 0.0 & 0 & 0.0 & 1 & 2.9 \\
2 & 8.7 & 0 & 0.0 & 0 & 0.0 & 2 & 5.7 \\
2 & 8.7 & 1 & 9.1 & 0 & 0.0 & 3 & 8.6 \\
3 & 13.0 & 0 & 0.0 & 0 & 0.0 & 3 & 8.6 \\
23 & 100.0 & 11 & 100.0 & 1 & 100.0 & 35 & 100.0 \\
& & & & & & & \\
22 & 95.7 & 11 & 100.0 & 1 & 100.0 & 34 & 97.1 \\
1 & 4.3 & 0 & 0.0 & 0 & 0.0 & 1 & 2.9 \\
23 & 100.0 & 11 & 100.0 & 1 & 100.0 & 35 & 100.0 \\
\hline
\end{tabular}

Note. $N=35$. Answers to the DEBA-Alcool/Drogues questionnaire (Tremblay et al., 2004).

${ }^{\mathrm{a}} n=34$ 
Table 3

Sample Levels of Substances and Substance Treatment Services Uses

\begin{tabular}{|c|c|c|c|c|c|c|c|c|}
\hline \multirow{3}{*}{ Variables } & \multicolumn{8}{|c|}{ Points of entry } \\
\hline & \multicolumn{2}{|c|}{$\begin{array}{l}\text { Criminal } \\
\text { justice } \\
\text { system }\end{array}$} & \multicolumn{2}{|c|}{$\begin{array}{l}\text { Hospital } \\
\text { emergency } \\
\text { rooms }\end{array}$} & \multicolumn{2}{|c|}{$\begin{array}{c}\text { Health } \\
\text { and } \\
\text { Social } \\
\text { Services } \\
\text { Centers }\end{array}$} & \multicolumn{2}{|c|}{ Total } \\
\hline & $n$ & $\%$ & $n$ & $\%$ & $n$ & $\%$ & $n$ & $\%$ \\
\hline \multicolumn{9}{|l|}{ Alcohol use $^{\mathrm{a}}$} \\
\hline Not at risk use & 13 & 56.5 & 5 & 45.5 & 0 & 0.0 & 18 & 51.4 \\
\hline Low dependence & 2 & 8.7 & 1 & 9.1 & 1 & 100.0 & 4 & 11.4 \\
\hline Problematic use & 4 & 17.4 & 3 & 27.3 & 0 & 0.0 & 7 & 20.0 \\
\hline High dependence & 4 & 17.4 & 2 & 18.2 & 0 & 0.0 & 6 & 17.1 \\
\hline Total & 23 & 100.0 & 11 & 100.0 & 1 & 100.0 & 35 & 100.0 \\
\hline \multicolumn{9}{|l|}{ Drugs use $^{\mathrm{a}}$} \\
\hline Not at risk use & 0 & 0.0 & 2 & 18.2 & 0 & 0.0 & 2 & 5.7 \\
\hline Low dependence & 1 & 4.3 & 1 & 9.1 & 0 & 0.0 & 2 & 5.7 \\
\hline Problematic use & 4 & 17.4 & 2 & 18.2 & 1 & 100.0 & 7 & 20.0 \\
\hline High dependence & 18 & 78.3 & 6 & 54.5 & 0 & 0.0 & 24 & 68.6 \\
\hline Total & 23 & 100.0 & 11 & 100.0 & 1 & 100.0 & 35 & 100.0 \\
\hline \multicolumn{9}{|l|}{$\begin{array}{l}\text { Drug most used/Drug with most negative } \\
\text { consequences }^{\mathrm{a}}\end{array}$} \\
\hline Cannabis & 5 & 21.7 & 5 & 55.6 & 1 & 100.0 & 11 & 33.3 \\
\hline PCP & 1 & 4.3 & 0 & 0.0 & 0 & 0.0 & 1 & 3.0 \\
\hline Hallucinogens & 2 & 8.7 & 0 & 0.0 & 0 & 0.0 & 2 & 6.1 \\
\hline Cocaine & 6 & 26.1 & 0 & 0.0 & 0 & 0.0 & 6 & 18.2 \\
\hline Other stimulants (excluding cocaine) & 6 & 26.1 & 4 & 44.4 & 0 & 0.0 & 10 & 30.3 \\
\hline Opiates & 3 & 13.0 & 0 & 0.0 & 0 & 0.0 & 3 & 9.1 \\
\hline Total & 23 & 100.0 & 9 & 100.0 & 1 & 100.0 & $33^{\mathrm{c}}$ & 100.0 \\
\hline \multicolumn{9}{|l|}{ Alcohol/drug associated use $\mathrm{e}^{\mathrm{a}, \mathrm{b}}$} \\
\hline Drug use only & 15 & 65.2 & 6 & 54.5 & 1 & 100.0 & 22 & 62.9 \\
\hline Alcohol use only & 1 & 4.3 & 3 & 27.3 & 0 & 0.0 & 4 & 11.4 \\
\hline Alcohol and drug use & 7 & 30.4 & 2 & 18.2 & 0 & 0.0 & 9 & 25.7 \\
\hline Total & 23 & 100.0 & 11 & 100.0 & 1 & 100.0 & 35 & 100.0 \\
\hline \multicolumn{9}{|l|}{$\begin{array}{l}\text { Number of substance treatment service use } \\
\text { during the last five years }{ }^{d}\end{array}$} \\
\hline 0 & 1 & 4.3 & 1 & 9.1 & 0 & 0.0 & 2 & 5.7 \\
\hline 1 & 4 & 17.4 & 5 & 45.5 & 0 & 0.0 & 9 & 25.7 \\
\hline 2 & 4 & 17.4 & 2 & 18.2 & 1 & 100.0 & 7 & 20.0 \\
\hline 3 & 4 & 17.4 & 0 & 0.0 & 0 & 0.0 & 4 & 11.4 \\
\hline 4 & 6 & 26.1 & 2 & 18.2 & 0 & 0.0 & 8 & 22.9 \\
\hline 5 & 2 & 8.7 & 0 & 0.0 & 0 & 0.0 & 2 & 5.7 \\
\hline 6 & 1 & 4.3 & 0 & 0.0 & 0 & 0.0 & 1 & 2.9 \\
\hline 7 & 0 & 0.0 & 1 & 9.1 & 0 & 0.0 & 1 & 2.9 \\
\hline 8 & 1 & 4.3 & 0 & 0.0 & 0 & 0.0 & 1 & 2.9 \\
\hline
\end{tabular}


Total

Note. $N=35$

${ }^{\mathrm{a}}$ Answers to the DEBA-Alcool/Drogues questionnaire (Tremblay et al., 2004). ${ }^{\mathrm{b}}$ For every use excepting not at risk one and for every drugs assessed (i.e. cannabis, PCP, hallucinogens, cocaine, others stimulants, opiates, sedatives). ${ }^{\mathrm{c}} n=33 .{ }^{\mathrm{d}}$ Answers to a homemade questionnaire (Fleury et al., 2009). 